\title{
AS RÁDIOS COMUNITÁRIAS COMO CONCRETIZADORAS DOS DIREITOS HUMANOS ECONÔMICOS, SOCIAIS E CULTURAIS
}

\section{Flávia Carlet}

Graduada em Ciências Jurídicas e Sociais pela Pontifícia Universidade Católica do Rio Grande do Sul. Integrante do Núcleo de Assessoria Jurídica Popular - NAJUP/RS.

e-mail: flavia_carlet@yahoo.com.br

RESUMO: O presente estudo versa sobre o papel das rádios comunitárias como concretizadoras dos direitos econômicos, sociais e culturais. Examina ainda alguns limites impostos às rádios comunitárias, aí compreendidos o monopólio dos meios de comunicação e a cultura jurídica positivista e seus prejuízos aos direitos humanos fundamentais.

PALAVRAS-CHAVE: Rádios comunitárias; Direitos humanos fundamentais; Monopólio dos meios de comunicação; Cultura jurídica. 
"Em regime de dominação de consciências, em que os que mais trabalham menos podem dizer a sua palavra e em que multidões imensas nem sequer têm condições para trabalhar, os dominadores mantêm o monopólio da palavra, com que mistificam, massificam e dominam. Nessa situação, os dominados, para dizerem a sua palavra, têm que lutar para tomá-la. Aprender a tomá-la dos que a detêm e a recusam aos demais, é um difícil, mas imprescindível aprendizado - é a pedagogia do oprimido".

Ernani Maria Fiori

\section{AS RÁDIOS COMUNITÁRIAS E O DIREITO HUMANO FUNDAMENTAL À COMUNICAÇÃO}

O direito humano fundamental à comunicação constitui-se numa necessidade humana básica, intimamente relacionado com o direito à vida e à liberdade. Entretanto, ainda que se reconheça a importância deste direito, previsto tanto na Constituição Federal Brasileira de 1988, quanto nos Tratados Internacionais de Direitos Humanos, há muito, vivemos uma situação na qual o povo não tem a possibilidade concreta de dizer sua palavra, falar para sua comunidade, exercer sua cidadania.

Não por acaso, foi justamente esta realidade que acabou por desencadear um fenômeno que percorreu, e ainda hoje percorre, a América Latina: a proliferação de meios de informação e comunicação alternativos, como resposta ao monopólio da palavra por parte daqueles que usufruem também do poder político e econômico. ${ }^{1}$

No caso do Brasil, foi ao longo do processo de democratização do país, entre os anos setenta e oitenta, que uma das experiências de comunicação alternativa mais importantes surgiu. Trata-se das rádios comunitárias, pequenas emissoras de radiodifusão, que propunham-se a transmitir as idéias e atividades de sua comunidade, servir como um espaço de articulação política e garantir o direito de comunicar.

${ }^{1}$ FERNANDEZ, Adrián José Padilla. Comunicação e cidadania na virada do século. In: DOWBOR Ladislau; IANNI, Otávio; RESENDE, Paulo-Edgar A; SILVA, Hélio (Orgs.). Desafios da Comunicação. Petrópolis: Vozes, 2001. p. 298. 
Não por acaso, para Armando Coelho, as rádios comunitárias ainda hoje "tratam-se de um dos mais legítimos movimentos populares, que reivindica nada mais nada menos do que a liberdade de expressão".2

Partindo destes apontamentos, podemos afirmar que as rádios comunitárias têm como principal objetivo fazer aquilo que as rádios comerciais não se propõe a fazer: exercer a comunicação livre, verdadeiramente democrática, de modo a oportunizar a difusão de idéias, de cultura, de promover a integração e o convívio social e ainda, servir ao interesse e desenvolvimento da própria comunidade.

Percebe-se, assim, que o compromisso com a comunidade é o grande diferencial deste tipo de radiodifusão. O que ela fizer e o que nela for dito, será sempre reflexo da voz de sua gente. Nesse sentido, ela destina-se a promover o desenvolvimento social, cultural e econômico da comunidade, de modo a traduzir-se num espaço de inclusão social e de democratização da comunicação.

\section{O DIREITO FUNDAMENTAL À COMUNICAÇÃO EXERCIDO ATRAVÉS DAS RÁDIOS COMUNITÁRIAS E AS DIMENSÕES DE DIREITOS FUNDAMENTAIS}

Foi com o reconhecimento e a consagração dos direitos fundamentais pelas primeiras Constituições que assumiu relevo as denominadas dimensões de direitos fundamentais, geradas pelo reconhecimento de novas necessidades básicas e intimamente relacionadas às evoluções do Estado Liberal para o moderno Estado Social e Democrático de Direito.

O Estado Liberal, que valorizava as relações particulares na sociedade e pregava que o direito público não deveria invadir searas dominadas pelo então direito privado, resultou na conquista da primeira série de direitos fundamentais. Estes direitos, referem-se aos chamados direitos de primeira dimensão, afirmados como direitos do indivíduo frente ao Estado e traduzidos nos direitos civis e políticos, como o direito à vida, à liberdade, à propriedade e à igualdade. ${ }^{3}$

\footnotetext{
${ }^{2}$ COELHO NETO, Armando. Rádio Comunitária Não é Crime. São Paulo: Ícone, 2002. p. 23.

${ }^{3}$ SARLET, A Eficácia dos Direitos Fundamentais. Porto Alegre: Livraria do Advogado, 1998. p. 48-49.
} 
A partir da segunda metade do século XIX, as relações sociais até então existentes alteraram-se, provocando uma nova configuração do Estado por força do novo cenário histórico, impulsionado pela Revolução Industrial e pelo surgimento de movimentos reivindicatórios que expressavam seu clamor pelas garantias e cumprimento dos direitos econômicos, sociais e culturais. ${ }^{4}$

Estes direitos fundamentais, que têm na igualdade seu princípio basilar, caracterizam-se ainda hoje por outorgarem ao indivíduo direitos a prestações sociais estatais como assistência social, saúde, educação e trabalho. ${ }^{5}$ Ademais, os direitos de segunda dimensão também podem ser considerados como uma densificação do princípio da justiça social, além de corresponderem às reivindicações das classes menos favorecidas ${ }^{6}$.

Ao final do século $X X$, percebe-se o surgimento dos direitos fundamentais da terceira dimensão, chamados também de direitos de fraternidade ou de solidariedade, caracterizados como direitos de titularidade coletiva, muitas vezes indefinida e indeterminável o que reclama novas técnicas de garantia e proteção. ${ }^{7}$

No rol de direitos desta dimensão, estão os direitos à paz, à autodeterminação dos povos, ao desenvolvimento, ao meio ambiente e à qualidade de vida, direito à conservação e utilização do patrimônio histórico cultural e à comunicação. ${ }^{8}$

Esta breve digressão histórica dos modelos de Estado e suas dimensões de direitos fundamentais nos oportuniza perceber, o quão interligados encontram-se os direitos humanos fundamentais.

Neste sentido, inclusive, tem sido a concepção contemporânea de direitos humanos, porquanto ela parte do pressuposto que todas as dimensões de direitos são

${ }^{4}$ KAUFMANN, Rodrigo Oliveira. A dicotomoa DireitoPúblico-Direito Privado. Revista Direitos Fundamentiase Estado democrático de Direito. Porto Alegre: Síntese, 2003. p. 23.

${ }^{5}$ SARLET, Ingo. Op Cit., p. 49.

${ }^{6}$ SARLET, Ingo. Op Cit., p. 50.

${ }^{7}$ SARLET, Ingo. Op. Cit, p. 51.

${ }^{8}$ SARLET, Ingo. Op. Cit., p. 51. 
concebidas como uma unidade interdependente e indivisível. ${ }^{9}$ Interdependente, pois entende-se que nenhuma dimensão substitui a outra, mas sim, todas expandem-se, cumulam-se e complementam-se em constante dinâmica de interação; indivisível, pois esvazia-se qualquer das dimensões de direitos, quando não assegurado o direito de qualquer a uma das demais. ${ }^{10}$

Partindo de tal entendimento, o direito à comunicação - como direito humano fundamental que é - quando exercido livremente através das rádios comunitárias, encontra-se absolutamente indissociável de quaisquer das quatro dimensões referidas, porquanto devido a seu caráter comunitário, fundado no respeito ao ser humano, à liberdade, à solidariedade, à igualdade e à participação, acaba por concretizar não apenas os direitos civis e políticos, mas principalmente os direitos econômicos, sociais e culturais, conforme comprovar-se-á a seguir.

\section{AS RÁDIOS COMUNITÁRIAS COMO CONCRETIZADORAS DOS DIREITOS HUMANOS ECONÔMICOS SOCIAIS E CULTURAIS}

Conforme visto a pouco, as rádios comunitárias atendem a um determinado segmento social, no caso as comunidades - estas não raro marginalizadas em relação à economia dominante - que encontraram neste tipo de radiodifusão a possibilidade de exercerem sua plena cidadania, sua liberdade de expressão e informação e de se desenvolverem econômica e culturalmente.

No âmbito social, como um dos mais evidentes benefícios propiciados pelas rádios comunitárias, podemos referir a prestação de serviços de utilidade pública, como a divulgação de campanhas sociais de vacinação infantil, contra a dengue e a febre amarela, de prevenção de DST-AIDS, de combate à desidratação infantil e de eliminação de todas as formas de preconceitos. ${ }^{11}$

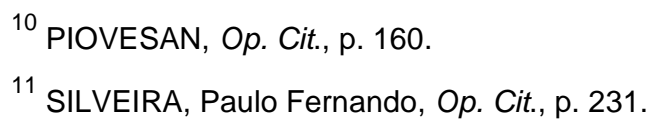

${ }^{10}$ PIOVESAN, Op. Cit., p. 160.

11 SILVEIRA, Paulo Fernando, Op. Cit., p. 231.

9 PIOVESAN, Flávia. Direitos Humanos e o Direito Constiucional Internacional. São Paulo: Max Limonad, 1997. p. 160. 
Podemos citar ainda o freqüente uso da radiodifusão comunitária na busca de soluções a problemas recorrentes nos bairros mais pobres das cidades, como a falta d'água ou de luz. Através de seus microfones, as comunidades mobilizam-se no sentido de pensar conjuntamente formas de viabilizar a superação de seus problemas.

Nesse mesmo sentido, Cláudia Klein, presidente da Rádio Comunitária Novo Barreiro, situada no Rio Grande do Sul, refere:

Em nosso caso, a rádio comunitária ajuda a mobilizar e a informar a população. Nessa época de seca, por exemplo, um exemplo de mobilização que ocorre é o "Grito da Terra". O pessoal divulga através do programa as agendas semanais dos movimentos sociais, tanto de ações de reivindicação quanto de reuniões, para que a comunidade fique sabendo. Então, claro que a rádio é um instrumento poderoso de mobilização social. ${ }^{12}$

No âmbito econômico, podemos trazer como exemplo o incremento no comércio local, à medida que os pequenos comerciantes conseguem publicizar os seus produtos através das rádios comunitárias, mediante o pagamento de um preço irrisório, a título de apoio cultural. ${ }^{13}$

Assim, aquele comerciante que divulgava seu produto em uma rádio comercial, pagando muito mais caro por isso, passa a poder fazê-lo a preço muito menor. Ou ainda, aquele que tinha que divulgar seu produto na rádio da cidade vizinha, pode passar a fazê-lo na rádio comunitária de sua localidade, alcançando assim o públicoalvo que the interessa. E por fim, o comerciante que nunca pôde utilizar desta prerrogativa para anunciar seus produtos, passa a ter a chance de fazê-lo dado o baixo custo dos anúncios nas rádios comunitárias. Tais situações são facilmente identificáveis com estabelecimentos como padarias, oficinas e minimercados de qualquer comunidade que possui a sua rádio comunitária.

Quanto ao aspecto cultural, as rádios comunitárias proporcionam a valorização das raízes culturais de sua comunidade, a preservação da tradição e dos seus

12 KLEIN, Cláudia. Rádios Comunitárias e a Mobilização Social. Frederico Westphalen. Associação Brasileira de Rádios Comunitárias da Região do Planalto Médio, 19 mar. 2005. Seminário Jurídico da Entidade. Entrevista concedida a Flávia Carlet e à advogada Soraia da Rosa Mendes.

${ }^{13}$ KLEIN, Cláudia. Idem. 
costumes, além de facilitarem a descoberta de pessoas talentosas na área da música, e do radialismo.

Complementando os exemplos citados, Armando Coelho refere que, não raras vezes, as rádios comunitárias ainda têm conseguido baixar o preço dos alimentos, providenciar remédios e cobertores, e implementar atividades sociais e educativas. Em outras palavras, é através delas que "serviços, vantagens, campanhas e mensagens tornam-se acessíveis, abrindo espaço para que a radiodifusão cumpra sua função social, entre elas, a de aproximar, fazer a conexão entre pessoas, idéias, integrando a comunidade". ${ }^{14}$

Pelo exposto até aqui, verifica-se o quanto as rádios comunitárias representam um importante instrumento na efetivação dos direitos humanos fundamentais, em especial os de segunda dimensão, qual sejam, os direitos econômicos, sociais e culturais, conforme verificado até aqui.

\section{LIMITES IMPOSTOS ÀS RÁDIOS COMUNITÁRIAS E SEU PREJUÍZO AOS DIREITOS SOCIAIS, ECONÔMICOS E CULTURAIS}

É sabido que a organização de movimentos sociais populares emerge das condições de miserabilidade e desigualdade social, geradoras de todas as formas de exclusão, vivenciadas pela maior parte da população brasileira. São esses movimentos que vem levando parcelas ou toda uma população a buscar formas de conquistar ou reconquistar espaços democráticos negados pela classe no poder. ${ }^{15}$

Não por acaso, para Jacques Alfonsin, essa multidão de brasileiros, aí compreendidos todos os "sem", são sujeitos que sofrem de três carências principais capazes de sacrificar sua própria dignidade como pessoa e cidadão: são carentes do ter, do poder e do ser, isto é, carentes dos efeitos jurídicos das três principais ordens

\footnotetext{
${ }^{14}$ COELHO NETO, Armando. Op. Cit., p. 68.

15 FESTA, Regina. Movimentos Sociais, Comunicação Popular e Alternativa. In: FESTA, Regina; SILVA, Carlos Eduardo Lins da. Comunicação Popular e Alternativa no Brasil. São Paulo: Paulinas, 1986. p. 11.
} 
que qualquer Constituição, de qualquer país, pretende garantir para todos, a ordem econômica, a ordem política e a ordem social. ${ }^{16}$

Como vimos, as rádios comunitárias emergem da iniciativa organizada desses sujeitos sociais, vítimas desses três tipos de carências, que nelas vêem um meio capaz alcançar a melhoria das condições de vida e o pleno exercício da cidadania.

Neste sentido, não é de surpreender o fato de que desde que as rádios comunitárias surgiram, não tem sido uma tarefa fácil para suas comunidades e seus operadores mantê-las no ar.

Diante da longa demora na tramitação dos seus processos para a autorização de funcionamento, elas têm sido alvo de constantes ações de repressão e criminalização, não raro, patrocinadas pelos donos dos grandes meios de comunicações que, sabidamente, para se perpetuarem no poder faz-se necessário um povo inculto e engessado em sua capacidade organizativa e mobilizadora.

Neste processo, conforme veremos adiante, o próprio judiciário, sob a influência de uma cultura jurídica legalista e excludente, acaba legitimando aquelas ações em detrimento da prevalência dos direito humanos fundamentais.

\subsection{O monopólio dos meios de comunicações}

A Carta Política brasileira, cujas bases estão fundadas no Estado Democrático de Direito, ao disciplinar sobre a comunicação social prevê em seu art. 220, parágrafo $5^{\circ}$ que os meios de comunicação social não podem, direta ou indiretamente, ser objeto de monopólio ou oligopólio. ${ }^{17}$ Positiva ainda, em seu art. 223, que o acesso a estes meios ocorrem por concessão temporária, ou seja, concedidas a prazo certo pelo poder público.

Assim, da leitura conjugada de ambos artigos, podemos concluir que os espaços de comunicação para uso de canais de rádio e televisão são públicos e que sua entrega só pode ocorrer mediante concessões feitas pelo governo, o que significa

${ }^{16}$ ALFONSIN, Jacques Távora. Cidadania e Participação Popular. In: Revista de Estudos Jurídicos, São Leopoldo, v. 31, n. 83, p. 66-67, set.-dez. 1998.

${ }^{17}$ CONSTITUIÇÃO, 2005 
portanto que este espaço não pode ter "donos". ${ }^{18}$ A estas importantes observações soma-se ainda a de que as concessões devem obrigatoriamente atender às finalidades educativas, culturais e informativas (art. 221 da CF/88) conforme comentado anteriormente.

Entretanto, ainda que a nossa Constituição discipline formalmente todas estas questões atinentes ao serviço da comunicação social, e ainda que um de seus principais fundamentos seja a soberania popular, é sabido que materialmente a organização e a concessão deste espaço tem se dado de forma contrária ao que dispõe a própria Carta.

Desse modo não há que se falar em espaço público, porquanto em sua maior parte, com o total alheamento do povo, tal espaço tornou-se objeto de monopólio de grupos empresariais privados e, portanto, encontra-se a serviço exclusivo dos interesses destes.

A discussão sobre o monopólio, inclusive, não pode deixar de lado alguns apontamentos sobre a temática que envolve o espectro eletromagnético, uma vez que quando falamos a respeito do direito de colocar no ar as ondas da radiodifusão comunitária ou comercial, estamos automaticamente nos referindo ao direito de acesso a esse espaço.

O espaço eletromagnético, por meio do qual as ondas de rádio se propagam constitui-se, reconhecidamente, em elemento integrante do Direito Ambiental, porquanto ele confunde-se com o ar, com a energia, mistura-se ao meio e ao ambiente.

Diante desta perspectiva, muito feliz é análise feita por Paulo Fernando Silveira, ${ }^{19}$ quando refere a necessidade de proteção e uso adequado do espectro eletromagnético, por parte Estado, para que todos dele desfrutem em condições de igualdade, tal qual se espera que ele o faça em relação ao uso da água e do meio ambiente de um modo geral.

18 Art. 223 - Compete ao Poder Executivo outorgar e renovar concessão e autorização para o serviço de radiodifusão sonora e de sons e imagens, observado o princípio da complementariedade dos sistemas privado, público e estatal.

${ }^{19}$ SILVEIRA, Paulo Fernando. Rádios Comunitárias, p. 145-146. 
Assim, refere o mesmo autor que o espectro eletromagnético é um bem de uso comum do povo, e não do governo, que tem o direito de usá-lo e dele desfrutar para a implementação de um de seus direitos humanos mais fundamentais: a comunicação. Ao governo, sublinha o autor, compete apenas gerenciar seu uso eqüitativo e adequado por todos os interessados em dele se utilizar. ${ }^{20}$

Convém sublinhar novamente que, sendo o espectro eletromagnético um elemento integrante do meio ambiente, um bem de uso comum merece ser tutelado e controlado. Portanto, o seu uso deve estar sob o controle do Estado, e não sob sua propriedade, para que seu aproveitamento se dê da melhor forma possível, em iguais condições e por todos os usuários.

Como bem lembra Armando Coelho, ${ }^{21}$ do mesmo modo que a terra, em especial as grandes propriedades, o espectro eletromagnético também necessita cumprir uma função social. ${ }^{22} \mathrm{E}$ quem vem cumprindo esta função são justamente as rádios comunitárias.

Sobre o trabalho delas frente ao monopólio das comunicações, Paulo Fernando refere:

É fácil perceber porque as oligarquias dominantes não querem o livre funcionamento das rádios comunitárias. Interessa-Ihes sobremaneira, para se perpetuarem no poder, que o povo continue na ignorância e na dispersão. Como o conhecimento liberta e a ignorância escraviza, a opção que remanesce para as lideranças minoritárias e oligárquicas, amantes do regime monárquico de distribuição do poder político (na base do favor) e da diferenciação das pessoas perante a lei, constitui-se numa única admissível variável: trilhar as veredas da desigualdade e, aguerridamente, não permitir distúrbio na manutenção do poder, utilizando-se para tal objetivo, o domínio da informação. ${ }^{23}$

De tudo o que foi dito até aqui podemos fazer, pelo menos, três importantes constatações. A primeira, de que há uma íntima relação entre o uso inadequado do bem comum, que é o espaço eletromagnético, e a formação dos monopólio das

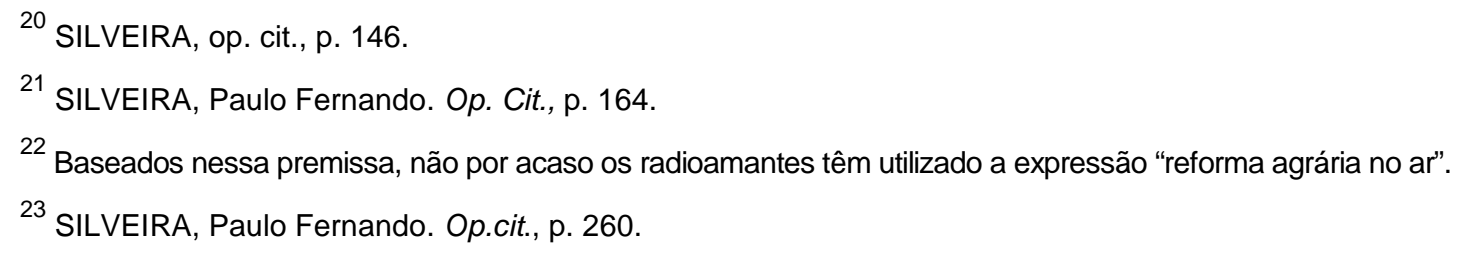


comunicações; a segunda, é que não podemos negar a nítida contradição entre o que prevê a nossa Constituição Federal em matéria de princípios democráticos e diretos humanos fundamentais e as práticas monopolistas exercidas em nossa sociedade; por fim a terceira constatação é a de que este círculo, enquanto perdurar, continuará a constituir um dos maiores limites à democratização da mídia, e por conseguinte à efetivação dos direitos humanos fundamentais.

\subsection{A Cultura Jurídica}

Além do monopólio dos meios de comunicação, outro limite imposto à atividade das rádios comunitárias, e que não podemos deixar de examinar refere-se ao da cultura jurídica tradicional dominante sobre o pensamento da maior parte dos operadores do direito.

De acordo com João Batista Herkenhoff, o pensamento dos juristas, ainda hoje, sofre grande influência do positivismo jurídico. Nesse sentido, explica ele, nas cátedras das faculdades, na doutrina exposta pelos livros e na jurisprudência dos tribunais, o que predomina é uma visão puramente estática do Direito. ${ }^{24}$ Acrescenta ainda que a cultura jurídica positivista traduz-se numa concepção conservadora, na qual o Direito aparece como "uma tecnologia de controle, organização e direção social".

Seguindo esta mesma linha de raciocínio, Sara Côrtes refere:

O positivismo é uma redução do Direito à ordem estabelecida (justo porque ordenado), só capta o direito quando vertido em normas, sem aceitar a crítica à injustiça das normas, ou por proclamar que elas contêm toda justiça possível, ou por não entender que o problema da injustiça é o jurídico. ${ }^{25}$

Sob esta concepção jurídica - provavelmente somada ao fato da maioria dos intérpretes das leis produzirem seu trabalho hermenêutico num "lugar social" de onde é

\footnotetext{
${ }^{24}$ HERKENHOFF, João Batista. Para Onde Vai o Direito? Reflexões sobre o papel do direito e do jurista. Porto Alegre: Livraria do Advogado. 1996. p. 35.

${ }^{25}$ CORTES, Sara da Nova Quadros. A "Dignidade Política do Direito" e a "Dignidade Jurídica da Política": no caminho de Roberto Lyra Filho. In: Direito Fundamentais e Estado Democrático de Direito. Porto Alegre: Síntese, 2003. p. 132.
} 
impossível a vista, alcançar toda a tragédia humana ${ }^{26}$ - estes operadores acabam por interpretar e aplicar o Direito à luz da hermenêutica tradicional, isto é, a partir de uma exegese literal e racional ${ }^{27}$ das disposições legais, em detrimento de uma exegese filológica ${ }^{28}$ e sociológica ${ }^{29}$.

Assim, deixa-se de apreciar a investigação dos motivos e dos efeitos sociais da lei, bem como de aplicar os textos legais de acordo com as necessidades das novas realidades. ${ }^{30}$

Para Herkenhoff, este modelo de cultura jurídica tem contribuído para a falta de sensibilidade e preparo dos operadores jurídicos no equacionamento dos conflitos resultantes das novas realidades sociais, uma vez que não estão eles preparados para interpretar e aplicar o Direito à luz de uma realidade absolutamente diversa daquela que orientou as grandes construções teóricas do passado. ${ }^{31}$

Em que pese o fato do pensamento jurídico nacional encontrar-se influenciado pela cultura jurídica positivista, não podemos deixar de mencionar, sob pena de incorrermos num superficialismo extremo, que tal pensamento também é influenciado pelo contexto social e cultural onde estão inseridos estes juristas.

Este entendimento, inclusive, há muito já foi explorado por Luis Alberto Warat em um de seus artigos, oportunidade em que referiu que as práticas cotidianas dos juristas sempre se encontram condicionadas por um conjunto de representações, costumes, preconceitos valorativos e teóricos que governam seus atos, suas decisões e suas atividades. ${ }^{32}$

${ }^{26}$ ALFONSIN, Jacques Távora. A Função Social da Cidade e da Propriedade Privada Urbana como Propriedade de Funções. In: ALFONSIN, Betânia; FERNANDES, Edésio. Direito à Moradia e Segurança da Posse no Estatuto da Cidade. Belo Horizonte: Fórum, 2004. p. 50.

${ }^{27}$ Segundo João Batista Herkennhoff, a exegese racional, é aquela que esvazia a lei de todo o conteúdo humano, deixando de fornecer informações sobre as razões sociais da lei (HERKENHOFF, Para Onde..., p. 36).

${ }^{28}$ É aquela na qual se persegue o conteúdo ideológico dos vocábulos para descobrir o que de subjacente existe neles (HERKENHOFF, João Batista. Op. Cit., p. 36).

${ }^{29}$ HERKENHOFF, João Batista. Op. Cit., p. 37.

30 HERKENHOFF, João Batista.Op. Cit., p. 37.

${ }^{31}$ HERKENHOFF, João Batista .Op. Cit., p. 42.

32 WARAT, Luis Alberto. O Sentido Comum Teórico dos Juristas. In: FARIA, José Eduardo (Org.). A Crise do Direito numa Sociedade em Mudança. Brasília: Unb, 1988. p. 31. 
Como elemento inerente a este contexto cultural, igualmente responsável por influenciar o posicionamento de nossos juristas, deve ser referida a cultura de massa ${ }^{33}$ propagadas pelos grandes meios de comunicação, sabidamente formadores de opinião e, portanto, do pensamento jurídico dominante..$^{34}$

Feitos estes breves apontamentos referentes à cultura jurídica que norteia 0 pensamento e o posicionamento da maior parte dos operadores do direito e, com o intuito de verificarmos como na prática esta cultura pode estar sendo um óbice à atividade das rádios comunitárias e aos direitos humanos fundamentais, transcrevemos agora duas decisões judiciais relativas à impossibilidade de funcionamento das mesmas.

AGRAVO DE INSTRUMENTO. INDEFERIMENTO DE LIMINAR FUNCIONAMENTO DE RÁDIO COMUNITÁRIA.

1. Não é permitido o funcionamento de radiodifusão que não detenha concessão, permissão ou autorização concedida pelo Poder Executivo.

2. Se a autoridade administrativa já tinha procedido da forma como lhe competia, ou seja, já tinha lacrado os equipamentos não se pode admitir o simples descumprimento da ordem emanada pela autoridade pública, sendo irrelevante o tempo de existência da rádio irregularmente instalada.

3. Agravo de instrumento conhecido e provido.

(AGRAVO NA SUSPENSÃO DE SEGURANÇA - Processo: 200304010561147 UF:RS Órgão Julgador: CORTE ESPECIAL Data da decisão: 26/02/2004 DJU DATA:10/03/2004 PÁGINA: 287 DJU DATA:10/03/2004 JUIZ VLADIMIR FREITAS)

AGRAVO DE INSTRUMENTO. MANDADO DE SEGURANÇA. DESLACRAMENTO DE APARELHO TRANSMISSOR. RÁDIO COMUNITÁRIA.

Ausente o "fumus boni iuris" autorizador da concessão de medida liminar, porquanto a atuação da recorrente encontra respaldo no legítimo exercício de seu poder de polícia inerente à atividade de fiscalização que detém a administração, deve ser reformada a decisão que deferiu a medida liminar para autorizar o deslacramento de aparelho transmissor da parte agravada.

Agravo provido.

${ }^{33}$ Segundo Edgar Morin, a cultura de massa é a cultura produzida em larga escala e que também em larga escala deve ser consumida através das modernas técnicas de difusão, comunicação e divulgação. Tal cultura é condicionada aos interesses individuais, e dirigida a uma massa social. Esta formada pelas classes, família, comunidades e grupos sociais (MORIN, 1970 apud. PERUZZOLO, Adair Caetano. Comunicação e Cultura. Porto Alegre: Sulina, 1972. p. 304).

${ }^{34}$ COELhO neto, Armando. Op. Cit., p. 170. 
(AGRAVO DE INSTRUMENTO - Processo: 200004010473245 UF: RS Órgão Julgador: TERCEIRA TURMA. Data da Decisão: 20/02/2001 DJU DATA: 21/03/2001 PÁGINA: 356 DJU DATA: 21/03/2001 JUIZA MARIA DE FÁTIMA FREITAS LABARRÈRE)

Em que pese todos os argumentos, alguns já expostos neste trabalho, em defesa do direito humano à comunicação exercido através das rádios comunitárias, ainda são muitas as decisões desfavoráveis a suas atividades. Da análise dos julgamentos acima referidos, pelo menos três conclusões podem ser extraídas.

A primeira refere-se ao fato de tais julgamentos terem sido proferidos justamente sob uma "visão estática" do Direito. O principal argumento utilizado no primeiro julgamento é o fato da rádio comunitária não portar a autorização para funcionamento. Logo, para este juiz, a efetivação do direito fundamental à comunicação está condicionada unicamente ao cumprimento da lei.

Entretanto, ao contrário do que prega o positivismo, o Direito não se restringe unicamente ao sistema de normas. O valor maior a ser alcançado não é a aplicabilidade da lei, mas sim a prevalência da Justiça. Nesse sentido, lembramos que em havendo um conflito entre a lei e a Justiça, deve prevalecer a Justiça "por fidelidade à própria lei que, não é um amuleto, mas deve ter como fim a justiça, o bem comum, os valores oriundos da ética, o progresso, o avanço da sociedade em direção a maior justiça, melhor distribuição de bens e maior igualdade". ${ }^{35}$

A segunda conclusão a que podemos chegar está relacionada com o fato de que, ao buscar uma solução para um caso concreto, os juizes, via de regra, não aplicam o direito à luz de uma interpretação sociológica, ou seja, não estão avaliando as conseqüências, os efeitos sociais da sua decisão. Ademais, sequer estão buscando solucionar os conflitos à luz de princípios basilares do nosso Estado Democrático de Direito como o da dignidade da pessoa humana. Aliás, talvez isto ocorra porque, como lembra Jacques Alfonsin, tal princípio transpira valores éticos,

${ }^{35}$ HERKENHOFF, João Batista. Op. Cit., p. 23. 
psicológicos e até sentimentais, ${ }^{36}$ todos certamente considerados impertinentes pela cultura jurídica positivista.

A terceira conclusão a que chegamos, e que consideramos igualmente importante referir, é que tendo em vista os princípios que norteiam a cultura jurídica positivista e seus reflexos nas decisões judiciais, clara está a opção política do jurista. Como bem refere João Batista Herkenhoff: "a ética pede do juiz neutralidade em face das partes enquanto tais. Mas a ética não pede que o juiz seja neutro quanto a valores. Essa neutralidade é impossível". ${ }^{37}$

Assim, entendemos que a cultura jurídica positivista faz claramente a opção política por um projeto de sociedade calcado no conservadorismo, na defesa dos privilégios, servindo à manutenção e ao aprofundamento das desigualdades sociais. Por tal pressuposto, e por todos os prejuízos que esta opção tem ajudado a causar a milhares de pessoas pobres, que legitimamente defendem seu direito à comunicação através das rádios comunitárias, é que também a consideramos como limite à efetivação dos direitos humanos fundamentais, em especial aos direitos econômicos, sociais e culturais, estes tão garantidos e respeitados pelas rádios comunitárias.

\section{CONSIDERAÇÕES FINAIS}

As rádios comunitárias representam um importante instrumento de emancipação popular e transformação social. Um meio imprescindível para o processo de democratização dos meios de comunicação do país e para a efetivação dos direitos humanos fundamentais, em especial os direitos econômicos, sociais e culturais.

Entendendo que as rádios comunitárias desempenham um papel educador, informador e politizador, garantindo a democratização da palavra, a prevalência dos direitos humanos e a efetivação da cidadania e da dignidade humana, qualquer óbice ao seu funcionamento, revela não apenas os interesses das classes dominantes em

\footnotetext{
${ }^{36}$ ALFONSIN, A Função Social da Cidade e da Propriedade Privada Urbana como Propriedade de funções. In: ALFONSIN, Betânia; FERNANDES, Edésio. Direito à Moradia e Segurança da Posse no e Estatuto da Cidade. Belo Horizonte: Fórum, 2004. p. 67.

${ }^{37}$ HERKENHOFF, João Batista. Op. Cit., p. 38.
} 
continuar agindo para que o povo não pense, não questione e não se mobilize, como também uma violação frontal a um Estado que se pretende Democrático e de Direito.

Neste sentido, enquanto o Poder Judiciário estiver norteado por uma cultura jurídica positivista, motivando suas decisões em fundamentos e métodos interpretativos mais preocupados em aplicar a lei do que fazer prevalecer o Direito e a Justiça, estará ferindo mortalmente um dos mais valiosos componentes para democracia de um país: o direito fundamental do seu povo de expressar-se e informar-se livremente. E nesse sentido, a luta deste mesmo povo para tomar e exercer um direito que a Constituição Ihe garante, reveste-se da mais absoluta legitimidade.

\section{REFERÊNCIAS BIBLIOGRÁFICAS}

ALFONSIN, Jacques Távora. A Função Social da Cidade e da Propriedade Privada Urbana como Propriedade de Funções. In: ALFONSIN, Betânia; FERNANDES, Edésio. Direito à Moradia e Segurança da Posse no Estatuto da Cidade. Belo Horizonte: Fórum, 2004.

BOBBIO, Norberto. A Era dos Direitos. Rio de Janeiro: Campus, 1992.

COELHO NETO, Armando. Rádio Comunitária Não é Crime. São Paulo: Ícone, 2002.

COMPARATO, Fábio Konder. A Democratização dos Meios de Comunicação de Massa. In: GRAU, Eros Roberto; GUERRA FILHO, Willis Santiago (Orgs.). Direito Constitucional: estudos em homenagem a Paulo Bonavides. São Paulo: Malheiros, 2001.

CORTES, Sara da Nova Quadros. A "Dignidade Política do Direito" e a "Dignidade Jurídica da Política": no caminho de Roberto Lyra Filho. In: Direito Fundamentais e Estado Democrático de Direito. Porto Alegre: Síntese, 2003.

FERNANDEZ, Adrián José Padilla. Comunicação e cidadania na virada do século. In: DOWBOR Ladislau; IANNI, Otávio; RESENDE, Paulo-Edgar A; SILVA, Hélio (Orgs.). Desafios da Comunicação. Petrópolis: Vozes, 2001.

FESTA, Regina. Movimentos Sociais, Comunicação Popular e Alternativa. In: FESTA, Regina; SILVA, Carlos Eduardo Lins da. Comunicação Popular e Alternativa no Brasil. São Paulo: Paulinas, 1986.

GOHN, Maria da Glória (Org.). Movimentos Sociais no Início do Século XXI. Petrópolis: Vozes, 2003.

GUARESCHI, Pedrinho A.; BIZ, Osvaldo. Mídia e Democracia. Porto Alegre, 2005.

HERKENHOFF, João Batista. Para Onde Vai o Direito? reflexões sobre o papel do direito e do jurista. Porto Alegre: Livraria do Advogado. 1996. 
KAUFMANN, Rodrigo de Oliveira. A "Dicotomia" Direito Público - Direito Privado. Revista Direitos Fundamentais e Estado Democrático de Direito. Porto alegre: Síntese, 2003.

KLEIN, Cláudia. Rádios Comunitárias e a Mobilização Social. Frederico Westphalen. Associação Brasileira de Rádios Comunitárias da Região do Planalto Médio, 19 mar. 2005. Seminário Jurídico da Entidade. Entrevista concedida a Flávia Carlet e à advogada Soraia da Rosa Mendes.

PIOVESAN, Flávia. Direitos Humanos e o Direito Constitucional Internacional. São Paulo: Max Limonad, 1997.

SARLET, Ingo Wolfgang. A Eficácia dos Direitos Fundamentais. Porto Alegre: Livraria do Advogado, 1998.

SILVEIRA, Paulo Fernando. Rádios Comunitárias. Belo Horizonte: Del Rey, 2001. 